\title{
Insulin resistance, compensatory hyperinsulinaemia, and coronary heart disease
}

\author{
G.M. Reaven, A. Laws \\ Stanford University School of Medicine, Division of Endocrinology, Palo Alto, California, USA
}

Professor Jarrett has reviewed (the few) epidemiological studies evaluating the association between plasma insulin concentration and coronary heart disease (CHD), and concluded that there is, "Unimpressive evidence of risk factor status", for plasma insulin levels [1]. We would agree that to date studies of this association are inconsistent, but attribute this to varying methodologies, sample sizes, and populations. Prof. Jarrett has also omitted any mention of plausible mechanisms for the relationship as recently summarized by Stout [2]. However, rather than critically reviewing the studies Prof. Jarrett has cited or not cited, we would like to place the emphasis where it belongs: on the evidence that insulin resistance and associated risk factors comprise a syndrome which is a CHD risk factor [3].

Insulin-mediated glucose uptake rate varies widely in individuals with normal glucose tolerance [3-6]; a defect in insulin action that does not differ substantially from that in patients with either impaired glucose tolerance or non-insulin-dependent diabetes can be demonstrated in up to a quarter of persons with normal glucose tolerance $[4,5]$. Insulin-resistant individuals with normal glucose tolerance are hyperinsulinaemic when compared to insulin-sensitive control subjects, and it seems likely that the increase in plasma insulin level permits them to overcome their defect in insulin action [3-6]. Fasting hyperglycaemia occurs when insulin-resistant individuals are no longer able to sustain a state of hyperinsulinaemia $[3,5]$. Thus, resistance to insulin-mediated glucose uptake

Corresponding author: G.M.Reaven, M.D., Stanford University School of Medicine, Division of Endocrinology, Gerontology and Metabolism, Department of Veterans Affairs Medical Center, 3801 Miranda Avenue, Crecc 182B Palo Alto, CA 94304 USA

Abbreviations: CHD, Coronary heart disease; TG, triglyceride; PAI-1, plasminogen-activator inhibitor-1. appears to be a common phenomenon, present in the majority of individuals who are glucose intolerant, as well as a substantial proportion of an apparently healthy population.

There is a large body of evidence linking insulin resistance and compensatory hyperinsulinaemia to a cluster of abnormalities that increase the risk of CHD. This concept, first introduced in 1988 [3], has since received considerable experimental support [7-9], and the number of abnormalities associated with insulin resistance, compensatory hyperinsulinaemia, and CHD has grown substantially [10].

Insulin resistance and compensatory hyperinsulinaemia play a central role in the regulation of lipoprotein metabolism [11], and the dyslipidaemia resulting from these abnormalities suggests one explanation for a link between insulin metabolism and CHD. Resistance to insulin-mediated glucose disposal and compensatory hyperinsulinaemia correlate strongly with VLDL-TG secretion rate and plasma TG concentration in both hypertriglyceridaemic and normotriglyceridaemic individuals [12-15]. Experimental manipulations which modify insulin action and/or plasma insulin concentration lead to predictable changes in VLDL-TG secretion rate and plasma TG concentration. For example, weight loss is associated with an increase in insulin-stimulated glucose uptake and decreases in plasma insulin concentration, hepatic VLDL-TG secretion, and plasma TG concentration [16]. In contrast, ingestion of a high carbohydrate diet leads to day-long parallel increases in plasma insulin and TG concentrations [17].

Once the plasma VLDL-TG pool-size increases, associated abnormalities of plasma lipoprotein metabolism develop. The best established of these is low high density lipoprotein (HDL)-cholesterol concentration [18]. When insulin-mediated glucose uptake is quantified in normal volunteers, the subset that is most insulin resistant has the highest insulin and TG 
and lowest HDL-cholesterol concentrations [19]. The associations of insulin resistance with plasma $T G$ and HDL-cholesterol concentrations are independent of obesity, either general or abdominal, and level of aerobic fitness as estimated by maximal oxygen consumption [19].

In addition to a low HDL-cholesterol, hypertriglyceridaemia is associated with two other important changes in lipoprotein metabolism that increase the risk of CHD: small, dense LDL-particles [20] and the accentuation of postprandial lipaemia [21]. Whether or not these changes are directly due to insulin resistance and compensatory hyperinsulinaemia, or simply secondary to the hypertriglyceridaemia that develops in subjects who are insulin resistant and hyperinsulinaemic, is not clear. However, we have recently shown that among 100 normal subjects, those with small, dense LDL particles are relatively insulin resistant, glucose intolerant, hyperinsulinaemic, hypertensive, hypertriglyceridaemic and have a lower HDL-cholesterol concentration [22]. We are not aware of any data in non-diabetic subjects demonstrating an association between insulin resistance, hyperinsulinaemia, and postprandial lipaemia, but we have shown such an association in patients with non-insulin-dependent diabetes mellitus [23].

The lipid abnormalities related to insulin resistance and compensatory hyperinsulinaemia are known to increase the risk of CHD. The strong association of low HDL-cholesterol to CHD risk has been shown in numerous studies [24-27]. In contrast, controversy continues as to whether or not hypertriglyceridaemia is an "independent" risk factor for CHD. Although high plasma TG and CHD are strongly correlated in univariate analysis, the relationship between hypertriglyceridaemia and CHD often loses statistical significance in multivariate analyses when variations in plasma HDL-cholesterol and glucose are taken into consideration [28-31]. However, as pointed out previously, plasma glucose, insulin, TG and HDL-cholesterol concentrations are themselves highly correlated. The problems with performing multivariate analysis to ascertain which of a series of variables is "independently" related to CHD, when the measures are themselves highly correlated, have recently been emphasized [30]. We have suggested previously that the examination of the contribution of this cluster of risk factors to CHD rather than the independent contribution of each variable may be the more appropriate analysis [32]. Furthermore, recent reports examining the contributions of HDL cholesterol and triglycerides to risk for atherosclerotic vascular disease showed the highest risk in men with low HDL cholesterol and high triglyceride concentrations $[26,27]$. Similarly, in the initial report demonstrating the increased risk for CHD associated with small, dense LDL cholesterol, it is notable that subjects with this lipoprotein abnormality had relatively low HDL cholesterol and high triglyceride concentrations [20], again demonstrating the cluster of metabolic $a b-$ normalities.

There is evidence that insulin resistance and compensatory hyperinsulinaemia are associated with changes that accentuate thrombosis formation by increasing coagulation and inhibiting fibrinolytic processes [9,33-35]. For example, plasminogen activatorinhibitor-1 (PAI-1) is associated with recurrent myocardial infarction in younger men, and is strongly inversely correlated with insulin and triglyceride concentrations, and directly correlated with insulin resistance $[9,33-36]$. Since insulin resistance, hyperinsulinaemia, and hypertriglyceridaemia are themselves highly correlated [3,12-15], it is not clear which of these changes is most important in regulation of PAI-1 levels. However, these observations provide further support for the role played by insulin resistance and hyperinsulinaemia in the pathogenesis of CHD.

Although no one would argue with the statement that CHD is the major cause of morbidity and mortality in patients with high blood pressure, many individuals, including Prof. Jarrett [37], would argue that insulin resistance and compensatory hyperinsulinaemia have nothing to do with the aetiology or clinical course of patients with hypertension. We would agree that not all patients with high blood pressure are insulin resistant and hyperinsulinaemic. We are also aware that not all epidemiologic studies show a correlation between plasma insulin concentration and blood pressure. On the other hand, neither of these observations prove that insulin resistance and compensatory hyperinsulinaemia are unrelated to either the aetiology and/or clinical course of a substantial portion of patients with high blood pressure.

Patients with high blood pressure, as a group, are resistant to insulin-mediated glucose uptake and hyperinsulinaemic when compared to a closely-matched population with normal blood pressure [38]. These abnormalities persist despite successful drug treatment of hypertension, and can be seen in both obese and non-obese individuals [38]. Furthermore, abnormalities of insulin metabolism can be discerned in normotensive first degree relatives of patients with high blood pressure [39, 40], but not in patients with secondary forms of hypertension [41]. The fact that insulin resistance and hyperinsulinaemia can be demonstrated in patients at risk for the development of hypertension raises the possibility that these abnormalities may play a role in the regulation of blood pressure. Further support for the view that insulin resistance and compensatory hyperinsulinaemia are involved in blood pressure regulation can be found in studies of rodent hypertension. Substitution of fructose for the carbohydrate conventionally present in rat 
chow leads to insulin resistance, hyperinsulinaemia and hypertension in Sprague-Dawley rats [42]. Subsequent studies in fructose-fed rats have shown that fructose-induced hypertension can be markedly attenuated if either insulin resistance and/or hyperinsulinaemia are prevented by either exercise training fructose-fed rats [43] or by chronically infusing somatostatin [44]. Hyperinsulinaemia has also been demonstrated in rats with genetic hypertension-including the spontaneously hypertensive rat, the Dahl saltsensitive rat, and the Milano hypertensive rat [45-47]. Furthermore, resistance to insulin stimulated glucose uptake has been demonstrated in adipocytes isolated from spontaneously hypertensive and Dahl salt-sensitive rats $[45,46]$.

Two major arguments have been advanced against the view that insulin resistance and hyperinsulinaemia are involved in blood pressure regulation. The first is that acute hyperinsulinaemia produced by infusing insulin into humans leads to vasodilation, and blood pressure does not increase [48]. In addition, blood pressure does not change when insulin is infused into dogs for periods of up to 2 weeks [49]. However, blood pressure does increase when rats are infused with insulin [50]. A second argument is that a relationship between insulin level and blood pressure cannot always be seen in population studies. For example, a recent report has shown that blood pressure and insulin concentration were significantly correlated in Caucasians, but not in Afro-Americans or Pima Indians [51]. However, other studies have shown that hypertensive Afro-Americans are insulin resistant and hyperinsulinaemic when compared to Afro-Americans with normal blood pressure [52, 53], raising obvious questions as to the significance of the lack of a relationship between blood pressure and insulin described in Afro-Americans in epidemiological studies [51].

The role of insulin resistance and compensatory hyperinsulinaemia in the clinical course of patients with high blood pressure appears to be less controversial. In the first place, these subjects tend to be glucose intolerant, and there is certainly evidence that this abnormality would increase their risk of CHD [3, $38,54,55]$. In addition, hyperglyceridaemia is commonly seen in patients with essential hypertension and in their first-degree relatives [38-40], as well as in dietary-induced and genetic forms of rodent hypertension [42-47]. The association between insulin resistance and compensatory hyperinsulinaemia in the development of hypertriglyceridaemia, as well as the relationship between an increase in plasma TG concentration and CHD, have already been discussed, and it should not be necessary to repeat at this juncture. Further bolstering the link between abnormal insulin metabolism, high blood pressure, and CHD is the recent observation that patients with high blood pressure and ECG evidence of CHD were insulin resistant and hyperinsulinaemic when compared to a matched group of patients with high blood pressure who did not demonstrate ischaemic ECG changes [56]. In light of these considerations, we would suggest that there is ample evidence that the development of CHD in patients with hypertension may be secondary to the defects in insulin metabolism that exist in these subjects.

There is now abundant evidence from both epidemiological and case-control studies that insulin resistance and/or hyperinsulinaemia, dyslipidaemia, hypertension and defects in haemostatic function cluster in individuals $[3,7-19,31-35,38-40,52,53]$. In this brief presentation we have tried to summarize evidence that resistance to insulin-mediated glucose disposal and compensatory hyperinsulinaemia predispose individuals to develop this cluster of associated abnormalities that increase the risk of CHD. Although we have cast the abnormalities of insulin metabolism in a central role, we are aware that questions remain to be answered regarding the relationship between the metabolic, haemodynamic, and haemostatic abnormalities associated with insulin resistance and compensatory hyperinsulinaemia; issues that we cannot address within the constraints of this presentation. However, despite these unresolved questions, we think available information strongly supports the view that resistance to insulin-mediated glucose uptake, and its consequences, are involved to a substantial degree in the cause and clinical course of $\mathrm{CHD}$.

\section{References}

1. Jarrett RJ (1994) Why is insulin not a risk factor for coronary heart disease? Diabetologia 37: 945-947

2. Stout RW (1990) Insulin and atheroma: 20 -yr perspective. Diabetes Care 13: 631-654

3. Reaven GM (1988) Role of insulin resistance in human disease. Diabetes 37: 1495-1607

4. Hollenbeck G, Reaven GM (1987) Variations in insulin-stimulated glucose uptake in healthy individuals with normal glucose tolerance. J Clin Endocrinol Metab 64: 1169-1173

5. Reaven GM, Hollenbeck CB, Chen Y-DI (1989) Relationship between glucose tolerance, insulin secretion, and insulin action in non-obese individuals with varying degrees of glucose tolerance. Diabetologia 32: 52-55

6. Reaven GM, Brand RJ, Chen Y-DI, Mathur AK, Goldfine I (1993) Insulin resistance and insulin secretion are determinants of oral glucose tolerance in normal individuals. Diabetes 42: 1324-1332

7. Haffner SM, Stern MP, Hazuda HP, Mitchell BD, Patterson JK (1990) Cardiovascular risk factors in confirmed prediabetic individuals: does the clock for coronary heart disease start ticking before the onset of clinical diabetes? J Amer Med Assoc 263: 2893-2898

8. Landin K, Tengvory L, Smith U (1990) Elevated fibrinogen and plasminogen activator (PAI-1) in hypertension are related to metabolic risk factors for cardiovascular disease. $\mathrm{J}$ Intern Med 227: 273-278

9. Ferrannini E, Haffner SM, Mitchell BD, Stern MP (1991) Hyperinsulinaemia: the key feature of a cardiovascular and metabolic syndrome. Diabetologia 3: 416-422 
10. Laws A, Reaven GM (1993) Insulin resistance and risk factors for coronary heart disease. In: Ferrannini E (ed) Clinical endocrinology and metabolism: insulin resistance and disease. Baillière Tindall, London, pp 1063-1078

11. Reaven GM, Chen Y-DI (1988) Role of insulin in regulation of lipoprotein metabolism in diabetes. Diabetes/Metab Rev 4: 639-652

12. Reaven GM, Lerner RL, Stern MP, Farquhar JW (1967) Role of insulin in endogenous hypertriglyceridemia. J Clin Invest 46: 1756-1767

13. Olefsky JM, Farquhar JW, Reaven GM (1974) Reappraisal of the role of insulin in hypertriglyceridemia. Am J Med 57: $551-560$

14. Tobey TA, Greenfield M, Kraemer F, Reaven GM (1981) Relationship between insulin resistance, insulin secretion, very low density lipoprotein kinetics and plasma triglyceride levels in normotriglyceridemic man. Metabolism 30:165-171

15. Garg A, Helderman JH, Koffler M, Ayuso R, Rosenstack J, Raskin P (1988) Relationship between lipoprotein levels and in vivo insulin action in normal young white men. Metabolism 37: 982-987

16. Olefsky JM, Reaven GM, Farquhar JW (1974) Effects of weight reduction on obesity: studies of carbohydrate and lipid metabolism, J Clin Invest 53: 64-76

17. Farquhar JW, Frank A, Gross RC, Reaven GM (1966) Glucose, insulin, and triglyceride responses to high and low carbohydrate diets in man. J Clin Invest 45: 1648-1656

18. Zavaroni I, Dall'Aglio E, Alpi O et al. (1985) Evidence for an independent relationship between plasma insulin and concentration of high density lipoprotein cholesterol and triglyceride. Atherosclerosis 55:259-266

19. Laws A, Reaven GM (1992) Evidence for an independent relationship between insulin resistance and fasting plasma HDL-cholesterol, triglyceride and insulin concentrations. J Int Med 231: 25-30

20. Austin MA, Breslow JL, Hennekens CH, Buring JE, Willett WS, Krauss RM (1988) Low-density lipoprotein subclass patterns and risk of myocardial infarction. J Am Med Assoc 260: 1917-1921

21. Patsch JR, Miesenböck G, Hopferwieser Tet al. (1992) Relation of triglyceride metabolism and coronary artery disease: studies in the postprandial state. Arterioscler Thromb 12: $1336-1345$

22. Reaven GM, Chen Y-DI, Jeppesen J, Maheux P, Krauss RM (1993) Insulin resistance and hyperinsulinemia in individuals with small, dense, low density lipoprotein particles. J Clin Invest 92: 141-146

23. Chen Y-DI, Swami S, Skowronski R, Coulston A, Reaven GM (1993) Differences in postprandial lipemia between patients with normal glucose tolerance and noninsulin-dependent diabetes mellitus. J Clin Endocrinol Metab 76:172177

24. Miller GJ, Miller NE (1975) Plasma-high-density-lipoprotein concentration and development of ischaemic heartdisease. Lancet 1: 16-19

25. Castelli WP, Doyle JT, Gordon Tet al. HDL cholesterol and other lipids in coronary heart disease. Circulation 55: 767772

26. Manninen V, Tenkanen L, Koskinen P et al. (1992) Joint effects of serum triglyceride and LDL cholesterol and HDL cholesterol concentrations on coronary heart disease risk in the Helsinki heart study: implications for treatment. Circulation 85: $37-45$

27. Assmann G, Schulte H (1992) Relation of high-density lipoprotein cholesterol and triglycerides to incidence of atherosclerotic coronary artery disease (the PROCAM experience). Am J Cardiol 70: 733-737
28. Hulley SB, Rosenman RH, Bawol RD, Brand RJ (1980) Epidemiology as a guide to clinical decisions. The association between triglyceride and coronary heart disease. $\mathrm{N}$ Engl J Med 302: 1383-1389

29. Criqui MH, Heiss G, Cohn R et al. (1993) Plasma triglyceride level and mortality from coronary heart disease. N Engl J Med 328: 1220-1225

30. Austin MA (1991) Plasma triglyceride and coronary heart disease. Arterioscler Thromb 11:2-14

31. Reaven GM (1993) Are triglycerides important as a risk factor for coronary disease? Heart Dis Stroke 2: 44-48

32. Laws A, King AC, Haskell W, Reaven GM (1991) Relation of fasting plasma insulin concentration to high density lipoprotein cholesterol and triglyceride concentrations in men. Arterioscler Thromb 11: 1636-1642

33. Juhan-Vague I, Alessi MC, Vague P (1991) Increased plasma plasminogen activator inhibitor 1 levels. A possible link between insulin resistance and atherothrombosis. Diabetologia 34: $457-462$

34. Potter van Loon BJ, Kluft C, Radder JK, Blankenstein MA, Meinders AE (1993) The cardiovascular risk factor plasminogen activator inhibitor type $I$ is related to insulin resistance. Metabolism 42: 945-949

35. Juhan-Vague I, Thompson SG, Jespersen J, on Behalf of the ECAT Angina Pectoris Study Group (1993) Involvement of the hemostatic system in the insulin resistance syndrome: a study of 1500 patients with angina pectoris. Arterioscler Thromb 13: 1865-1873

36. Hamsten A, Wiman B, Defaire U, Blomback M (1985) Increased plasma level of a rapid inhibitor of tissue plasminogen activator in young survivors of myocardial infarction. $\mathrm{N}$ Engl J Med 313: 1557-1563

37. Jarrett RJ (1992) In defence of insulin: a critique of syndrome X. Lancet 340: 469-471

38. Reaven GM (1991) Relationship between insulin resistance and hypertension. Diabetes Care 14:33-38

39. Ferrari P, Weidmann P, Shaw S et al. (1991) Altered insulin sensitivity, hyperinsulinemia, and dyslipidemia in individuals with a hypertensive parent. Am J Med 91: 589-596

40. Facchini F, Chen Y-DI, Clinkingbeard C, Jeppesen J Reaven GM (1992) Insulin resistance, hyperinsulinemia, and dyslipidemia in nonobese individuals with a family history of hypertension. Am J Hypertens 5: 694-699

41. Shamiss A, Carroll J, Rosenthal T (1992) Insulin resistance in secondary hypertension. Am J Hypertens 5: 26-28

42. Hwang I-S, Ho H, Hoffmann BB, Reaven GM (1987) Fructose-induced insulin and hypertension in rats. Hypertension 10: $512-516$

43. Reaven GM, Ho H, Hoffman BB (1988) Attenuation of fructose-induced hypertension in rats by exercise training. Hypertension 12: 129-132

44. Reaven GM, Ho H, Hoffmann BB (1989) Somatostatin inhibition of fructose-induced hypertension. Hypertension 14: $117-120$

45. Reaven GM, Chang H (1991) Relationship between blood pressure, insulin concentration, and insulin action in SHR and WKY rats. Am J Hypertens 4: 34-38

46. Reaven GM, Twersky J, Chang H (1991) Abnormalities of carbohydrate and lipid metabolism in Dahl rats. Hypertension 18: 630-635

47. Dall'Aglio E, Tosini P, Ferrari P, Zavaroni I, Passeri M, Reaven GM (1991) Abnormalities of insulin and lipid metabolism in Milan hypertensive rats. Am J Hypertens 4: 773775

48. Anderson EA, Mark AL (1993) The vasodilator action of insulin: implications for the insulin hypothesis of hypertension. Hypertension 21: 136-141 
49. Hall JE, Brands MW, Kivlighn SD, Mizelle HL, Hildebrandt A, Gaillard CA (1990) Chronic hyperinsulinemia and blood pressure. Hypertension 15: 519-527

50. Brands MW, Hildebrandt DA, Mizelle HL, Hall JE (1991) Sustained hyperinsulinemia increases arterial pressure in conscious rats. Am J Physiol 260: R764-R768

51. Saad M, Lillioja S, Myomba BL et al. (1991) Racial differences in the relation between blood pressure and insulin resistance. N Eng1 J Med 324: 733-739

52. Falkner B, Hulman S, Tennenbaum J, Kushner H (1990) Insulin resistance and blood pressure in young black men. Hypertension 16: 706-711
53. Falkner B, Hulman S, Kushner H (1993) Insulin-stimulated glucose utilization and borderline hypertension in young adult blacks. Hypertension 22:18-25

54. Fuller JH, Shipley MJ, Rose G, Jarrett RJ, Keen H (1980) Coronary-heart-disease risk and impaired glucose tolerance. Lancet i: 1373-1376

55. Vaccaro O, Ruth KJ, Stamler J (1992) Relationship of postload plasma glucose to mortality with 19-yr follow-up. Diabetes Care 13: 1328-1334

56. Sheu WH-H, Jeng C-Y, Shieh S-M et al. (1992) Insulin resistance and abnormal electrocardiograms in patients with high blood pressure. Am J Hypertens 5: 444-448 